\title{
Wisdom from a medical elder
}

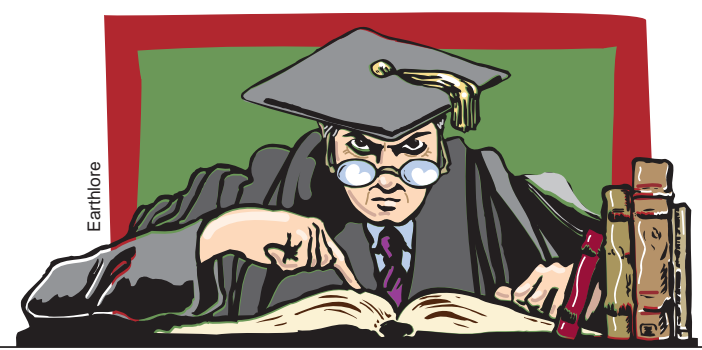

The following excerpts are transcribed from a speech delivered by Dr. Eugene A. Stead in Durham, NC, in October 2002 on the occasion of his 93rd birthday. They represent the extemporaneous musings of a true medical pioneer who was perhaps the foremost American clinician of the second half of the 20th century. Although William Osler is generally creditied with defining the state and practice of clinical medicine earlier in the last century, few would dispute Dr. Stead's subsequent importance as a pre-eminent medical educator. He was responsible for training more heads of medical departments than any other physician of his day, and is also credited with conceptualizing and creating the Physician Assistant Program while Chairman of Medicine at Duke University Medical Center. This 2-year educational postgraduate program provides support to the physician workforce by extending the reach of board-certified physicians. Ultimately, Dr. Stead's trainees served to influence the diffusion of present clinical paradigms across the United States.

The following remarks reflect the speaker's frustration with the present state of the very system of medical education on which he thrived and to which he contributed so much. Dr. Stead challenges us to move beyond the status quo and risks inviting the criticism of the profession he so proudly served for over 50 years. Perhaps, as Dr. Stead intimates, it's time for another Flexner-style report to recommend reforms to medical education. By doing so, we may create opportunities to correct some of the shortcomings in contemporary health care and to better serve our patients.

\section{Robert L. Bloomfield}

The E.A. Stead Jr. Director of Archives

of Medical Education

The Evergreen Clinic

James L. Derrick

Associate Director

The Evergreen Clinic

Carolyn F. Pedley

Associate Professor

Department of Medicine

Wake Forest University Medical Center

Winston-Salem, NC
... There hasn't been one medical school that has failed since the publication of the Flexner Report. I think that this is an interesting fact, that either demonstrates medical schools are so wonderful, or the situation is so critical that nobody wants to examine it. ...

If you look at other businesses, that is, other prominent "big businesses" at the time of the Flexner Report, you'll find that only about $5 \%-7 \%$ are still in business. That's an interesting comparison to the history of medical schools, which number in the hundreds. ... That occurrence should make you somewhat suspicious, since major medical schools have a rather rigid system, which doesn't allow them to change with the changing times. They must be protected in some unusual way; of course I think that they are.

You cannot practice ... without a four-year medical degree. ... You cannot become a medical doctor unless you pass two qualifying examinations. These exams are not based entirely upon what we know about caring for patients, but mainly upon questions of whether we have a MD degree from an accredited medical school; it doesn't matter how good of a medical school it is.

In order to sit for the qualifying exams, you are required to have a medical school degree. That piece of parchment is relevant, indeed. In our country, therefore, we have a monopoly on the creation of skilled medical manpower in the hands of schools which are mostly in the mode they were in during the Flexner Report.

The questions at issue then are, "Are there medical schools ... that are not interested mainly in their own profits, but are concerned primarily in the care of the patients ..." and "Is it in our best interest to continue with the present medical school [system]?”

You must appreciate the fact that among all of the present and affordable online education [options available], we now have a private school marketplace [that is] no longer asking for charity [alone to fund their initiatives], 
but [is clearly suggesting to the public] that medical education is worth spending money for. The online educational institutions advertise "You want to come to our school, we will charge you some money and give you a good education conveniently - while you are at home or work. You do not have to go to a college campus of a fancy school, a bucolic place where people enjoy exploring the grounds."

I predict that the medical school of the future will be in a little building, and will not have a great campus; it will be online. There's not a medical school in this country that will allow you to take courses online toward a medical degree. Not a single one.

... Most people don't notice a monopoly, or that medical schools do not have a major interest in serving rural areas, the underprivileged, or those underserved. Many people know very little about medical education, and most do not know that the first two years of medical school are predominantly a matter of having a good memory. ... Medicine is thought of as a very illustrious profession, yet it's not that difficult to learn. Thus, the commonly associated arrogance of physicians has always irritated the heck out of me.

... I wonder in truth if medical schools are not passé. Could the first two years of medical school possibly be learned at many fine undergraduate colleges, since these early years rely heavily on memory, predominantly? These colleges can bring you up to date on the present state of medicine. I consider the rest of medical school to be mainly "apprenticeship." Medical schools now tend to operate in specialized areas, the apprenticeship is no longer concerning the general care of the patient; it is, presently, quite narrow. In a university hospital you carry orders from department to department; most of the time these orders are not fully carried out, so it's sort of an operation fraught with inconsistencies. I don't think many people have honestly looked at medical schools the way that I have. I am a product of one of the best; I had a great career in spite of my criticisms.

I was not particularly interested in providing service to all people. I never thought about that until my later years; I knew the medical school wasn't that interested in that goal either. Now that I have grown older, I realize how ignorant I was for most of my career, and I am a little ashamed of what a slow learner I was.

\section{Eugene A. Stead}

Eugene Stead is a former Chairman of the Department of Medicine, Duke University Medical Center, and a retired distinguished Professor of Medicine, Veterans Administration Medical Center, Durham, NC.

\section{Essay Prize Winner}

\section{Darwinian pursuits with interruptions by Huxley: a brief pontification on medical education}

\section{Farrah Mateen}

A troop of newly arrived students, very young, pink and callow, followed nervously, rather abjectly, at the Director's heels. Each of them carried a note-book, in which, whenever the great man spoke, he desperately scribbled. Straight from the horse's mouth. It was a rare privilege. -Aldous Huxley, Brave New World, ${ }^{1}$ p. 15

\footnotetext{
t's no secret: to get into a Canadian medical school nowadays is no small accomplishment. With only 16 schools, taking limited numbers each year, undergraduate medical students, on their first day of classes, are already overachieving superstars. Most will walk in with at least one degree they are musicians, teachers, art his-
}

torians and researchers, not to mention other health care professionals. Many will have lived abroad, taught English, learned multiple languages and performed charity work in a remote rural village. They will be scholastically brilliant (most transcripts unblemished by introductory chemistry) and athletically impressive, principal chair of the local orchestra, leaders of this or that student society, call the Mona Lisa La Foconde and be completely capable of volunteering in umpteen different ways (most naturally including the classic candy striper). They are the kind of people that, idiomatically, "make you sick." What's worse, many are al- ready budding ophthalmologists and pediatric neurosurgeons the day they walk in the door.

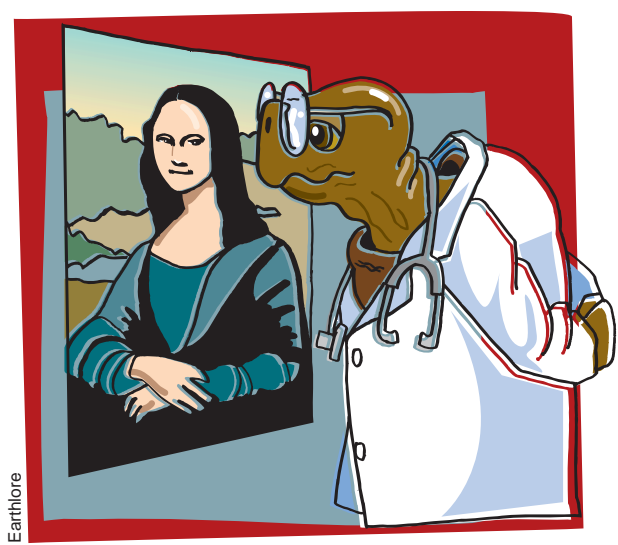

